\title{
Informed consent for elective surgery-what is best practice?
}

\author{
Owen A Anderson I Mike J Wearne
}

J R Soc Med 2007; 100:97-100

Increasing medico-legal litigation, ${ }^{1}$ and the desire to provide patients with more say concerning their own treatment, has highlighted the issue of informed consent and how it is obtained. In order for a patient to make a sensible decision concerning his or her treatment they need appropriate information. This may occur via discussions with medical/nursing staff, via the media/internet, or from speaking with friends who have undergone a similar procedure. However, it chiefly occurs during the acquisition of informed consent, during which the risks and benefits of any surgical procedure are explained.

The principles of this paper are applicable to consent for any elective surgical procedure. However, we highlight examples from phacoemulsification cataract surgery, the most widely performed elective ophthalmic operation. This is an ideal example of elective surgery, as it can be performed with an equal outcome both early and late in the natural history of cataract, with the timing of surgery heavily reliant upon the patient's visual demands, anxieties and expectations. The discussion is focused predominately on UK Department of Health guidelines and English law, but many of the underlying ethical principles are still applicable to patients overseas.

\section{WHO SHOULD OBTAIN INFORMED CONSENT?}

Informed consent for elective surgery is often obtained by junior medical staff, during pre-assessment clinics, or on the day of surgery. This may include pre-registration House Officers (PRHOs) (F1 grade-Modernizing Medical Careers) or Senior House Officers (SHOs). Current guidance states that the person obtaining consent must either (1) be capable of performing the procedure themselves; or (2) have received specialist training in advising patients about the procedure. ${ }^{2}$

Junior medical staff may be placed in a position where they fulfil neither of the above two criteria. Certain specialist procedures, such as cataract surgery or elective

Department of Ophthalmology, Eastbourne District General Hospital, Eastbourne, UK

Correspondence to: Owen A Anderson, Moorfields Eye Hospital, 162 City Road, London EC1V 2PD, UK

E-mail: anderson.owen@doctors.org.uk angiography, have very specific risks, which may not be adequately covered in undergraduate education. A thorough understanding is required to be able to appropriately advise the patient. Instruction in obtaining informed consent is therefore vital.

\section{TIMING OF INFORMED CONSENT}

For consent to be valid the patient must (1) be competent to take the particular decision; (2) have received sufficient information to make a decision; and (3) not be acting under duress. $^{2,3}$

The last point may be an issue if consent is obtained upon the day of surgery. Most patients will have firmly decided to proceed before attending for surgery. However, a minority may develop doubts upon learning about the procedure in more detail, during the consent process. If these doubts arise on the day of surgery the patient may feel under duress to proceed, as all the arrangements have been made. Therefore it would be wiser to obtain informed consent at the time of listing in clinic, when the risks and benefits are often explained. The patient will feel under less pressure to proceed, and hence will not be acting under duress.

Informed consent remains valid for an indefinite period, allowing advance consent to be sought, providing that the patient's condition has not changed, and/or new information concerning the proposed intervention or alternative treatments have not come to light in the intervening period. ${ }^{3}$ It is good practice, if consent was obtained in advance, to confirm consent at the time of surgery.

\section{EXPLANATION OF THE PROCEDURE}

Consent should begin with a brief explanation of the planned operation, including the anaesthetic involved. It is wise to describe what the patient may expect to experience during surgery, if under a local anaesthetic. Medical jargon should be avoided as it only serves to reduce understanding. Sufficient information to make a decision should also include an explanation of (1) the risks and benefits involved; (2) any alternative treatments; and (3) the risks and benefits of doing nothing. ${ }^{2,3}$ 


\section{EXPLANATION OF POTENTIAL RISKS}

The Department of Health consent form came into circulation during 2002-03. ${ }^{2}$ Its format includes specific sections for documentation of the intended benefits and serious or frequently occurring risks. Debate arises as to how much to mention. ${ }^{4,5}$ A polarized opinion would present one argument that the patient should know everything, with the opposing argument stating that this would only serve to confuse the patient. The issue of how much to explain to a patient is debatable $e^{4,5}$ with the following quotation highlighting the dilemma faced by many doctors:

'A patient may make an unbalanced judgement because he is deprived of adequate information. A patient may also make an unbalanced judgement if he is provided with too much information and is made aware of possibilities which he is not capable of assessing because of his lack of medical training, his prejudices or his personality.' (per Lord Templeman in Sidaway (1985) $1 \mathrm{AC} 871$ at 904, as cited by Lord Woolf in Pierce) ${ }^{6}$

Ultimately, the decision of what to mention lies with the consenting surgeon. Currently the Department of Health advises that a doctor:

(1) Should warn the patient of anything that poses a substantial risk of grave adverse consequences; $;, 7$

(2) Should mention significant risk that would affect the decision of a reasonable patient; ${ }^{6,8}$

(3) Is under a clear and legal obligation to tell the truth if asked a direct question. $6,8,9$

In practice, a complication that is likely to occur more than $1 \%$ of the time is often mentioned, but certain less frequent complications may be so grave that the doctor feels it wise to mention them. For example, permanent loss of vision following routine cataract surgery occurs in approximately 4 in 1000 cases $^{10}$ and should be routinely mentioned. Some complications are so extremely rare that they need not be routinely mentioned; however, if asked a direct question concerning the possible occurrence of such a complication, the doctor must answer truthfully. ${ }^{6,11,12}$

A key point to remember is the doctor's responsibility to inform a patient of 'a significant risk which would affect the judgement of a reasonable patient' (i.e. cause the patient to decline surgery). This is based on previous appeal judgements ${ }^{8}$ and is part of Department of Health guidance. ${ }^{3}$ This does not mean that the doctor is liable every time a complication occurs which he or she has not mentioned: it only applies to complications that may cause a reasonable practice this includes serious or frequently occurring risks which may tip the risk/benefit balance, in that patient's mind, in favour of declining surgery. As all patients are different it is the doctor's duty to highlight patients who are unsure, and give them more discussion time to reach an appropriate decision.

The goal is to inform the patient well enough to allow them to make a balanced decision. Too little information fails to inform, while too much information may be counter-productive and only lead to confusion. In practice, listing potential surgical complications may be meaningless to many patients, unless they are readily described in a manner easily understandable to a lay person (e.g. infection instead of endophthalmitis). It may be more meaningful to explain how these complications may affect the patient in the future (e.g. permanently worse vision or even blind eye).

Preceding surgery, patient's knowledge of the procedure varies. Kiss et al. surveyed patients who were about to undergo cataract surgery, and who were giving informed consent. They found that $40 \%$ of patients had not informed themselves about the surgery prior to the consent process, with $60 \%$ believing that cataract surgery held no risk of severe, sight-threatening complications. ${ }^{13}$ Information regarding surgery (including risks) has been shown to have positive/ neutral effect upon the decision to proceed, ${ }^{13,14}$ supporting a complete and frank provision of relevant information. Patients consider informed consent to be important and expect all pertinent information to be conveyed. ${ }^{15}$

Some patients may wish to know little or nothing about the risks, but this should not be assumed. One must presume that all patients wish to be well informed about benefits and risks, and paternalistic assumptions are not acceptable. If the converse is true, however, then one should abide by the patient's wishes and document this to be the case. ${ }^{2,16}$

Providing patients with an idea of the frequency of complications helps put a certain degree of proportion into the patient's mind. It is clearer to express risk in terms of proportions (1 in 100, 4 in 1000) as opposed to percentages, which may not be understood.

\section{EXPLANATION OF POTENTIAL BENEFITS}

After explaining the risks it is sensible to remind the patient of the potential benefits of undergoing the procedure. The frequency of success can be balanced against the frequency of risk. Appreciation of this balance underpins the concept of informed consent.

\section{EXPLANATION OF ALTERNATIVE TREATMENTS}

Any alternative options should be briefly explained, putting them in context by highlighting the pros and cons compared to the current procedure. 


\section{EXPLANATION OF THE OUTCOME IF SURGERY WAS NOT PERFORMED}

This is particularly important in elective surgery, where the immediate result of no surgery is status quo. The long term possibility of spontaneous resolution or worsening of the condition and the way surgery may influence this is worth highlighting.

\section{THE CONSENT FORM TO USE}

The Department of Health has produced a series of consent forms, each designed for a specific purpose. ${ }^{17}$ For most procedures involving local anaesthesia with or without sedation, or general anaesthesia, consent form one is suitable. However, the following circumstances require the use of a different form:

\section{Patient $\geqslant 18$ years without the capacity to give consent}

A patient will not be legally competent to give consent if they are unable to comprehend and retain information material to the decision, and/or they are unable to weigh and use this information in coming to a decision. ${ }^{3}$

In these circumstances consent form four must be used. If capacity is temporarily lost it may be wise to defer elective surgery until it returns. However, if permanently lost (e.g. dementia), surgery may proceed if felt to be in the patient's best interest, unless the patient had previously refused the procedure before they lost capacity.

\section{Patients $<18$ years without the capacity to give consent}

If a child is unable to comprehend and retain information material to the decision, and/or is unable to weigh and use this information in coming to a decision, then consent must be sought from a parent using consent form two. However, if a child has the mental capacity to perform the above two tasks, and is therefore able to give informed consent, then consent is legal and consent form one may still be used. Legally, the person with parental responsibility does not need to countersign for the consent to be valid, but in practice it is wise to also ask the parent to countersign. For competent children giving consent for therapeutic procedures beneficial to their health this ability to legally give their own consent is covered by section 8 of the Family Law Reform Act 1969 for children aged 16-17 and by the principle of Gillick competence for those who are younger. 3,18 While a child under the age of 18 may be able to legally give their consent, should they refuse their consent to a procedure, this can be overridden by someone with parental responsibility for that child.
Summary of Department of Health consent forms and their indications

Form 1

Adults and children with the capacity to give consent for any procedure

Form 2

Children without the capacity to give consent for any procedure

Form 3

Adults with the capacity or children with or without the capacity to give consent for procedures without the use of anaesthetic or sedation

Form 4

Adults without the capacity to give consent for any procedure

\section{Procedures not requiring anaesthesia}

Consent form 3 is suitable for adults and children with capacity, and parents signing on their child's behalf. It is only valid for procedures where consciousness is not impaired and no anaesthetic is used. Its use is therefore limited in elective surgical procedures.

If a person is able to give their consent but physically unable to sign the form, then another person may sign as a witness that consent was given.

\section{Other consent forms}

In court, disputes often arise about what information was given. It may not be enough to say, 'I usually give these potential complications for this procedure.' Usual practice will not hold if the court believes the patient more than the doctor. Therefore clear documentation of the risks and benefits explained is the doctor's best defence. ${ }^{11}$ As a result, specific consent forms have been designed listing specific information for specific procedures. ${ }^{19}$ While this provides standardization, informed consent must still involve a verbal explanation of what is written on the form.

\section{USE OF ADDITIONAL MEDIA}

Use of audio visual information and leaflets can be useful, and indeed are recommended. ${ }^{2,20}$ However, it is not sufficient to discharge the duty of explaining risks by simply giving out a leaflet. ${ }^{11}$ Additional information should be supplemental to, not a replacement, for verbal consent.

\section{CONCLUSION}

Routine elective surgery is a relatively standardized procedure. The potential risks of surgery are well known, and in the absence of additional pathology the frequency of their occurrence is also well known. Despite this the risks routinely mentioned by medical staff during informed consent will vary due to a combination of personal practice, personal experience and variable training. Some degree of 
variation is necessary, according to individual patient's needs.

In this article, no emphasis has been placed upon signing of the consent form. Although this action often constitutes completion of the consent process, it in no way should be considered as being part of the 'acquisition' of informed consent. This can only be obtained through a two-way, balanced discussion with the patient. A signature, without a balanced discussion, does not constitute informed consent.

We advocate that patients should ideally be asked for their consent at the time of listing for surgery. All new junior medical staff, if unfamiliar with the procedure, should undergo teaching in obtaining informed consent for that procedure. This may be best performed informally by a senior member of staff. All patients should, as a minimum, be informed about the risk of complications that pose a substantial risk of grave adverse consequences. With regard to cataract surgery, this would mean complications leading to permanently worse vision. Further discussion should be tailored to the patient's needs, with clear documentation of risks explained. A well written leaflet should be provided, explaining any medical jargon.

Consent is an opportunity to guide the patient to the right decision for them, and also dispel any unrealistic expectations concerning the procedure. Ultimately it is an opportunity to create a relationship of openness and trust between doctor and patient, which may help if operative complications are encountered. With high health-care expectations, a poorer than expected outcome may lead to surprise and subsequent anger: good patient education, during the informed consent process, is the surgeon's chance to forge a relationship with the patient and make sure that the patient's expectations are realistic.

\section{Summary points}

- Make sure you are suitably qualified to take informed consent for that particular procedure

- Choose the appropriate consent form to use

- Aim to gain informed consent before the day of the procedure

- Explanation of

○ Procedure

$\bigcirc$ Risks and benefits

Alternative treatments

$\bigcirc$ Risks and benefits of doing nothing

- Avoid the use of medical jargon

- Do not rush a decision if more time is needed

Competing interests None declared.
Financial support None.

Proprietary or financial interest None.

\section{REFERENCES}

1 Mavroforou A, Michalodimitrakis E. Physicians' liability in ophthalmology practice. Acta Ophthalmol Scand 2003;81:321-5

2 Department of Health (UK). Good Practice in Consent Implementation Guide: Consent to Examination or Treatment. London: Department of Health publications, 2001. Available at http://www.dh.gov.uk/ PolicyAndGuidance/HealthAndSocialCareTopics/Consent/ ConsentGeneralInformation/fs/en

3 Department of Health (UK). Reference Guide to Consent for Examination or Treatment. London: Department of Health publications, 2001. Available at http://www.dh.gov.uk/PolicyAndGuidance/ HealthAndSocialCareTopics/Consent/ConsentGeneralInformation/fs/en

4 Mirnezami AH. The impractical nature of informed consent. bmj.com 2002. Available at http://bmj.com/cgi/eletters/324/7328/39

5 Young PJ. What is reasonable informed consent? bmj.com 2002. Available at http://bmj.com/cgi/eletters/324/7328/39

6 Teuten B, Taylor D. 'Don't worry my good man-you won't understand our medical talk': consent to treatment today. $\mathrm{Br} J$ Ophthalmol 2001;85:894-6

7 Sidaway v Board of Governors of the Bethlem Royal Hospital (1985) AC 871

8 Pearce v United Bristol Healthcare NHS Trust (1999) PIQR 53

9 General Medical Council (UK). Seeking Patients' Consent: The Ethical Considerations. London: GMC, 1998. Available at http://www.gmcuk.org/guidance/library/consent.asp

10 Desai P, Minassian DC, Reidy A. National cataract surgery survey 1997-8: a report of the results of the clinical outcomes. $\mathrm{Br} J$ Ophthalmol 1999;83:1336-40

11 Skene L, Smallwood R. Informed consent: lessons from Australia. BMJ 2002;324:39-41

12 Rogers v Whitaker (1992) 175 CLR 479.

13 Kiss CG, Richter-Mueksch S, Stifter E, et al. Informed consent and decision making by cataract patients. Arch Ophthalmol 2004;122:94-8

14 Vallance JH, Ahmed M, Dhillon B. Cataract surgery and consent; recall, anxiety, and attitude toward trainee surgeons preoperatively and postoperatively. J Cataract Refract Surg 2004;30:1479-85

15 Scanlan D, Siddiqui F, Perry G, Hutnik CML. Informed consent for cataract surgery: what patients do and do not understand. J Cataract Refract Surg 2003;29:1904-12

16 Department of Health (UK). Consent - what You Have A Right To Expect. A Guide For Adults. London: Department of Health publications; 2001. Available at http://www.dh.gov.uk/PolicyAndGuidance/ HealthAndSocialCareTopics/Consent/ConsentGeneralInformation/fs/en

17 Department of Health (UK). Consent Forms. London: Department of Health publications, 2006. Available at http://www.dh.gov.uk/ PolicyAndGuidance/HealthAndSocialCareTopics/Consent/ ConsentGeneralInformation/fs/en

18 Gillick v West Norfolk and Wisbech AHA [1986] AC 112

19 The Royal College of Ophthalmologists. Consent Form. Available at http: / / www.rcophth.ac.uk/scientific/docs/consentform04.pdf

20 The Royal College of Ophthalmologists. Consent For Cataract SurgeryInformation For Patients. Available at http://www.rcophth.ac.uk/ scientific/docs/consentinfo04.pdf 